\title{
Enhanced self-regulation nonlinear PID for industrial pneumatic actuator
}

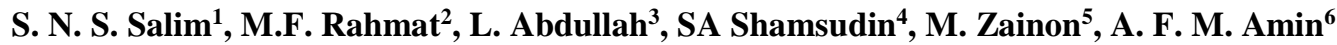 \\ ${ }_{1,5,6}$ Faculty of Electrical \& Electronic Engineering Technology Universiti Teknikal Malaysia Melaka, Melaka, Malaysia \\ ${ }^{2}$ Department of Control and Mechatronic Engineering, Faculty of Electrical Engineering, \\ Universiti Teknologi Malaysia, Malaysia \\ ${ }^{3}$ Faculty of Manufacturing Engineering Universiti Teknikal Malaysia Melaka, Malaysia \\ ${ }^{4}$ Faculty of Machanical Engineering Universiti Teknikal Malaysia Melaka, Malaysia
}

\section{Article Info}

Article history:

Received Jun 30, 2019

Revised Mar 12, 2019

Accepted Mar 21, 2019

\section{Keywords:}

Dead-zone compensation

PID

Pneumatic actuator

PSO

Self-regulation nonlinear

function $(\mathrm{SNF})$

\begin{abstract}
The present article describes the improvement of Self-regulation Nonlinear PID (SN-PID) controller. A new function is introduced to improve the system performance in terms of transient without affecting the steady state performance. It is used to optimize the nonlinear function available on this controller. The signal error is reprocessed through this function, and the result is used to tune the nonlinear function of the controller. Furthermore, the presence of the dead zone on the proportional valve is solved using Dead Zone Compensator (DZC). Simulations and experiments were carried out on the pneumatic positioning system. Comparisons between the existing methods were examined and successfully demonstrated.
\end{abstract}

Copyright (C) 2019 Institute of Advanced Engineering and Science. All rights reserved.

\section{Corresponding Author:}

S. N. S. Salim,

Faculty of Electrical and Electronic Engineering Technology,

Universiti Teknikal Malaysia Melaka,

Hang Tuah Jaya 76100 Durian Tunggal, Melaka, Malaysia.

Email: syednajib@utem.edu.my

\section{INTRODUCTION}

Compressed gas is a source of power that can perform various functions and pneumatics is classified in the fluid power controls which utilizes that compressed gas. It has been used in industries for many years due to several advantages such as inexpensive, fast in motion, high power to weight ratio, easy maintenance, unaffected by scorching heat and reputable. Additionally, it is also widely used in many automatic tasks as a replacement to hydraulic and electric servo motors. However, there are many factors that affect the control of pneumatic systems, including high nonlinearities due to high friction forces, dead band in the valve and compressibility of air [1-2]. These factors lead to the difficulty in achieving an accurate position.

As a consequence of many control strategies that were investigated by [3-12], researches in pneumatic positioning systems have grown considerably over the last 20 years. Since early 2000s, the advanced control strategies such as fuzzy logic control, adaptive control, neural network and so on were intensively explored and exercised to the pneumatic system. Nonetheless, over the past decade innumerable researchers have found that, when compared to other techniques, the technique that integrated with PID controller works better in the pneumatic positioning system. The abovementioned statement refers to the increment of the growth rate of publications written by [13-19]. A dynamic model of pneumatic actuator is distinguished by substantial nonlinearities as previously stated. Therefore, 
the utilization of standard linear controllers are hard to produce good performance for the system, particularly with variations in pressure and load. On the other hand, as deduced by [17, 20-22], it still can work by reconstructing the configuration or enhancing the adaptability of the controlled parameters.

[23] proposed a combination of conventional PID controller and neural network that has a high learning capability, adaptation and tackling nonlinearity. The experiments were carried out for each of the cases with and without external inertia loads, up to $20 \mathrm{kgcm} 2$. The proposed method showed a superior achievement and has the capability to countervail the disturbance compared to the conventional PID controller. An adaptive fuzzy PD controller was adopted to compensate the friction as recommended in another study conducted by [24]. The objective is to guarantee the stroke's movement to the target position occurs swiftly and accurately without significant overshoot. The settling time and steady state error under a constant load was acquired under $1 \mathrm{~s}$ and $0.3 \mathrm{~mm}$, independently, without significant overshoot as claimed by the authors. A Multi-model controller on the basis of a few fixed PD-controllers was suggested by [17] because of the disadvantage of adaptive controller which is slow to follow the parameter variations. This technique has succeeded in increasing the capacity to produce good performances.

In previous work, the Self-regulation Nonlinear Function (SNF) was introduced to generate a rate variation of the nonlinear function for NPID controllers [25]. However, there is still minor problem in method [25] in which, some disturbance on the cylinder movement occurs when SNF algorithm activated. In addition, there is also a slight delay with respect to the output. Thus, in this paper, an improvement for the said purpose was proposed. The uniqueness of this new approach lies in the introduction of a new equation for the denominator of the nonlinear function called deceleration factor $\eta$. The reasoning behind the introduction of this new equation is to avoid the occurrence of overshoot and retain the transient performance of the system with respect to the desired speed. In addition, the Dead Zone Compensator (DZC) was added to the system to cater the dead zone phenomenon normally occurred in the valve mechanism. In order to verify the capability of this controller, experiments were carried out. The comparisons with the existing methods (SNPID) were executed in reference to the transient and steady-state performance.

The structure of this paper is arranged as such: The research method is briefly explained in Section 2. The technique on how to determine the deceleration factor, $\square$ for ESN-PID controller is discussed in Section 3. Section 4 reports the experimental and simulation results using MATLAB/SIMULINK. Lastly, some conclusive statements are presented in section 5.

\section{RESEARCH METHOD}

In accordance with the Hardware in the Loop (HIL) approach, an experiment was conducted on the pneumatic actuator system. A comprehensive system configuration is shown in Figure 1. The coding was done using the Real-Time Windows Target (RTWT) toolbox and employed using MATLAB/ SIMULINK software. The test rig or physical model of the pneumatic positioning system is presented in Figure 2. The system being thought about consists of $5 / 3$ bi-directional proportional control valve (Enfield LS-V15s), Double acting with double rod cylinder, Non-contact micro-pulse displacement transducer with floating Magnet (Balluff BTL6), Data acquisition card (NI-PCI-6221 card), Pressure sensors (WIKA S-11), Personal Computer, and Compressor (Jun Air).

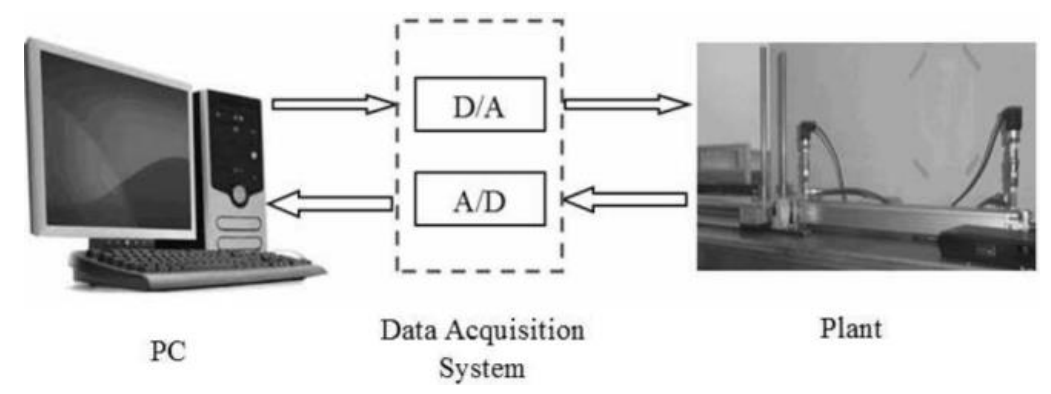

Figure 1. Configuration of the real plant and software 


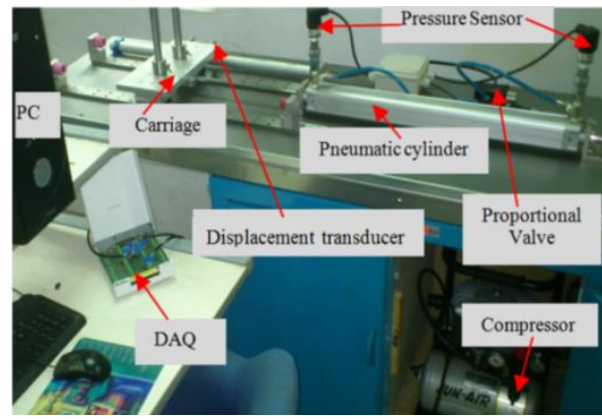

Figure 2. Test rig

\subsection{System model}

The System Identification was used to obtained the transfer function. This being said, 2000 data points constituting the input and output signals of the open loop system were gathered with a sampling time of 0.01 second. An iterative search through the prediction-error minimization (PEM) approach that generates a minimal prediction error variance when exercised to the working data was used to compute the estimated parameters. The parameters of the model were determined by reducing the cost function of the prediction errors via this approach. The discrete state-space equation was acquired by using this identification process and it is shown below.

$$
\begin{aligned}
& A=\left[\begin{array}{ccc}
2.846 & -1.350 & 8.544 \times 10^{-1} \\
2 & 0 & 0 \\
0 & 0.5 & 0
\end{array}\right] \quad B=\left[\begin{array}{c}
0.125 \\
0 \\
0
\end{array}\right] \\
& C=\left[\begin{array}{ccc}
-3.494 \times 10^{-2} & 3.765 \times 10^{-2} & -3.967 \times 10^{-2}
\end{array}\right] \quad D=[0]
\end{aligned}
$$

A continuous transfer function obtained through Zero Order Hold $(\mathrm{ZOH})$ conversion method is defined as:

$$
G p(s)=\frac{-0.507 s^{2}+6.385 s+92.490}{s^{3}+15.740 s^{2}+85.530 s+0.389}
$$

\subsection{Control design}

The primary objective is to achieve good results in controlling the position and continuing motion and this is achieved by using a simple design approach as emphasized by the conventional PID controller. Howbeit, this type of controller frequently unable to deliver best performance due to the rigidity of position control performance. A self-regulation nonlinear PID (SN-PID) controller was introduced by [17] to overcome this issue. N-PID is developed from the modification of the PID controller that integrated with automatic nonlinear gain and SN-PID controller is an improvement of the N-PID controller. The objective of this research is to design a controller with the displacement of the actuator that can reach the target in the fastest and most accurate way without any significant overshoot. Therefore, the controller was added with an extra function to countervail the nonlinearities of the system. This function will produce various values of nonlinear gain constantly to improve the performance, particularly in the transient part. Among the issues to be taken into account is the ability to maintain performance under various loads and pressures.

\subsection{Enhancement of self-regulation nonlinear PID}

Initially, the designing of the revised PID controller integrated with an automatic nonlinear gain was performed. The deficiencies in a conventional PID controller and its nonlinearities were overcome by using the automatic nonlinear gain, $k(e, \alpha, \gamma)$. An Enhanced Self-regulation Nonlinear PID (ESN-PID) controller is a combination of $k(e, \alpha, \gamma)$ and PID controller, where $k(e, \alpha, \gamma)$ is defined as a nonlinear function of error that relies on the generated values of $\alpha$ and $\gamma$ under the restriction of $0<k(e, \alpha, \gamma)<k\left(e_{\max }\right)$. $e$, is an error refers to the conditions given in (2). A new equation as written in (3) is proposed to replace the denominator of the nonlinear gain to make it more flexible. A new parameter known as deceleration factor is introduced to avoid large overshoot to the system. The system block diagram with the suggested controller is depicted in Figure 3. 


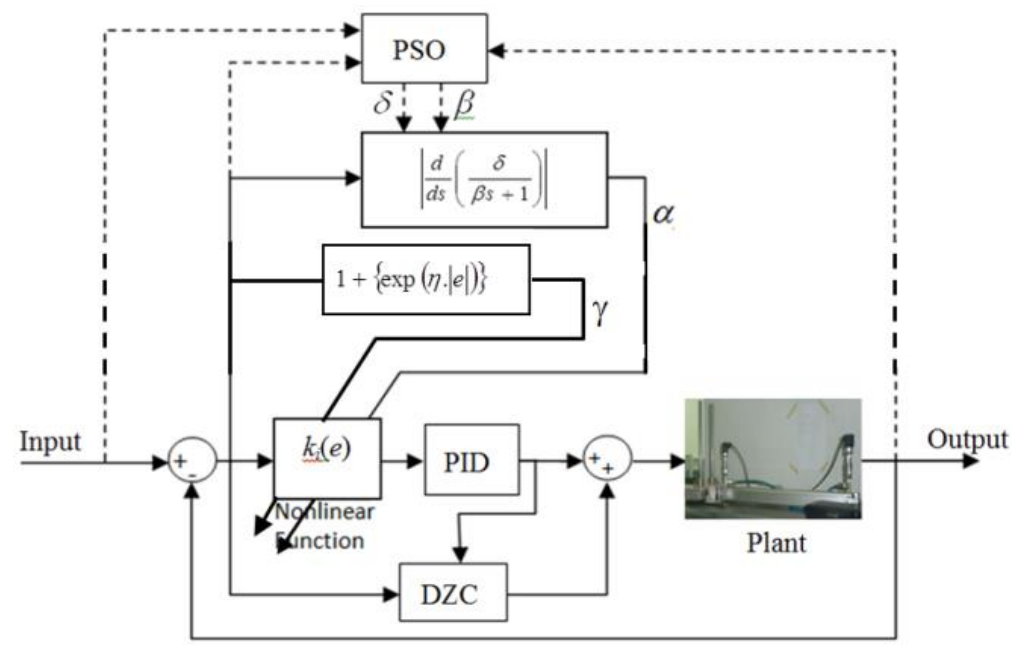

Figure 3. Enhanced self-regulation nonlinear PID (ESN-PID) controller

The overall function of the proposed nonlinear gain is:

$$
k(e, \alpha, \gamma)=\frac{\exp (\alpha e)+\exp (-\alpha e)}{\gamma}
$$

where:

$$
\begin{aligned}
& e=\left\{\begin{array}{cc}
e & |e| \leq e_{\max } \\
e_{\max } \operatorname{sign}(e) & |e|>e_{\max }
\end{array}\right. \\
& \gamma=1+\{\exp (-\eta \cdot|e|)\},(\eta>0)
\end{aligned}
$$

where:

$\alpha \quad$ - rate variation of nonlinear gain

$e_{\text {max }}$ - range of variation

$\eta \quad$ - deceleration factor and

$$
k\left(e_{\max }\right)=-\frac{1}{|G(j \omega)|}
$$

The value of $\alpha$ is generated on-line through the Self-regulation Nonlinear Function as presented in (5).

$$
\frac{\alpha(s)}{e(s)}=\frac{d}{d s}\left|\frac{\delta}{\beta s+1}\right|
$$

Consider the exponential decay represents the error signal, thus;

$$
U(s) G_{\delta, \beta}(s)=\left(\frac{A \delta}{\beta}\right)\left(\frac{1}{s+a} \cdot \frac{1}{s+1 / \beta}\right)
$$

Perform a partial fraction and this yield

$$
U(s) G_{\delta, \beta}(s)=\frac{A \delta}{(1-a \beta)(s+a)}+\frac{A \delta}{(a \beta-1)(s+1 / \beta)}
$$


Next, the inverse Laplace transform is used, which leads to

$$
\begin{aligned}
u(t) g_{\delta, \beta}(t) & =L^{-1}\left[U(s) G_{\delta, \beta}(s)\right] \\
& =\frac{A \delta}{1-a \beta} e^{-a t}+\frac{A \delta}{a \beta-1} e^{-\frac{1}{\beta} t}
\end{aligned}
$$

Then, by taking the derivative for Equation (8); and this resulted

$$
\alpha(t)=\frac{d}{d t}\left[u(t) g_{\delta, \beta}(t)\right]=\frac{A \delta}{1-a \beta}\left(\frac{1}{\beta} e^{-\frac{1}{\beta} t}-a e^{-a t}\right)
$$

Based on the initial value theorem, the next equation derived is

$$
\lim _{t \rightarrow 0}|\alpha(t)|=\lim _{t \rightarrow \infty}\left|\frac{A \delta}{1-a \beta}\left(\frac{1}{\beta} e^{-\frac{1}{\beta} t}-a e^{-a t}\right)\right|=\frac{A \delta}{1-a \beta}\left(\frac{1}{\beta}-a\right)
$$

Following that, using the final value theorem leads to

$$
\lim _{t \rightarrow \infty}|\alpha(t)|=\lim _{t \rightarrow \infty}\left|\frac{A \delta}{1-a \beta}\left(\frac{1}{\beta} e^{-\frac{1}{\beta} t}-a e^{-a t}\right)\right|=0
$$

Based on (3) and (9), it can be concluded that, to overcome the static friction, both parameters $\gamma$ and $\alpha$ are automatically generated to give a specific value of nonlinear gain at the initial phase. In this case, a steady state response is gained when the rate variation decreases starting from a definite value and ends at 0 . Meanwhile, the value of denominator $\gamma$ increases from a certain value and ended at 2 .

\section{DETERMINATION VALUE OF THE DESIGN PARAMETERS}

As previously described in [17], the Particle Swarm Optimization (PSO) technique was utilized to determine the design parameters of $\delta$ and $\beta$. The deceleration factor $\eta$ is a positive value selected by the user and is used to prevent the system response from overshoot. This value is adjusted starting from the low level until it obtained the optimum value. The $\eta$ value that exceeds the limit causes an overshoot to the system. The deceleration factor selected in this research is 0.2 . Figure 4 shows the variation of $\gamma$ in reference to the percentage of error in accordance with the selected values of $\eta$.

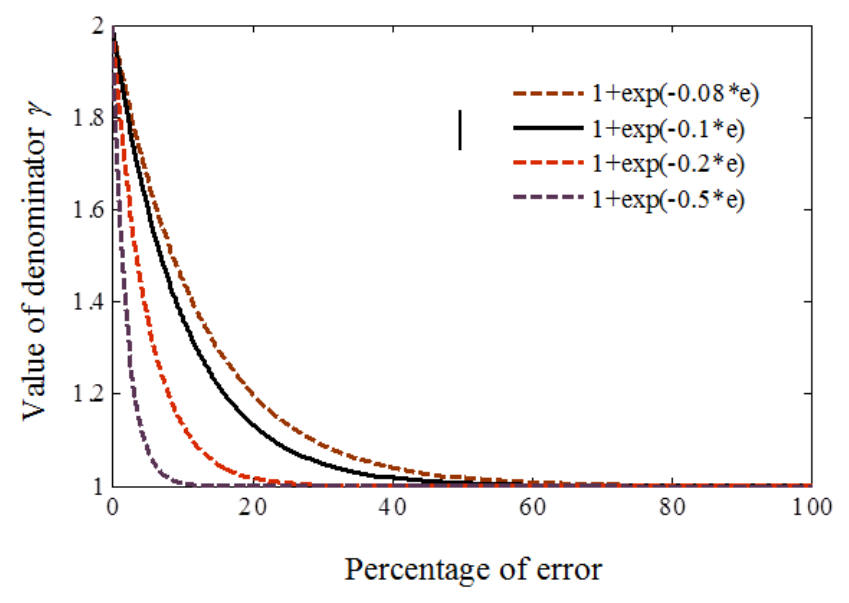

Figure 4. Various value of $\gamma$ in reference to the percentage of error 
A scaled error is an output generated by the nonlinear function, and it is stated as

$$
f(e)=k(e, \alpha, \gamma) \cdot e(t)
$$

A complete equation of the suggested ESN-PID controller is

$$
u_{P I D} \cdot f_{x}(e)=k_{p}(\cdot) e(t)+k_{i}(\cdot) \int_{0}^{t}[e(t)] d t+k_{d}(\cdot) \frac{d}{d t}[e(t)]
$$

where $(\bullet)$ proportionate to the controller with the time-varying gains that depends on the input and other variables.

\section{RESULTS AND DISCUSSION}

In order to assess the accomplishment of the pneumatic positioning system controlled according to the proposed method; simulations and experiments were conducted. The parameters of the controller and dead zone compensator are tabulated in Table 1 and Table 2, respectively. The simulated result of the output response procured from the system administered by SNPID and ESN-PID (consists of $\gamma$ function) is shown in Figure 5. The result exhibits that the proposed technique offers a slightly faster response compared to the existing technique without affecting the steady-state performance. The rise time and settling time decreased from $0.527 \mathrm{~s}$ to $0.461 \mathrm{~s}$, and $0.979 \mathrm{~s}$ to $0.828 \mathrm{~s}$, respectively.

Table 1. Parameters of enhanced SNPID controller

\begin{tabular}{cccc}
\hline \multirow{2}{*}{ Control strategies } & Parameter & $\begin{array}{c}\text { Control Parameters } \\
\text { Abbreviation }\end{array}$ & Value \\
\hline PID & Proportional Gain & $K p$ & 2.099 \\
& Integral Gain & $K i$ & $9.56 \times 10^{-3}$ \\
& Derivative Gain & $K d$ & 0.035 \\
\multirow{5}{*}{ SN-Function } & Filter & $N$ & 12.207 \\
& Param 1 & $\delta$ & 167.902 \\
& Param 2 & $\beta$ & 324.411 \\
$\gamma$-Function & Variation of Error & $e_{\max }$ & 1.350 \\
& Deceleration & $\eta$ & 0.100 \\
\hline
\end{tabular}

Table 2. Parameters of dead zone compensator

\begin{tabular}{cccc}
\hline Compensator & Parameter & Abbreviation & Value \\
\hline $\begin{array}{c}\text { Control value in } \\
\text { the range of } \\
\text { desired } \mathrm{s}_{\mathrm{ss}}\end{array}$ & $u_{e 0}$ & 0.010 \\
compensator & $\begin{array}{c}\text { +ve dead-zone } \\
\text { compensation } \\
\text {-ve dead-zone } \\
\text { compensation } \\
\text { Desired } \mathrm{e}_{\mathrm{ss}}\end{array}$ & $u_{p}$ & 0.500 \\
& $u_{n}$ & -0.650 \\
\hline
\end{tabular}

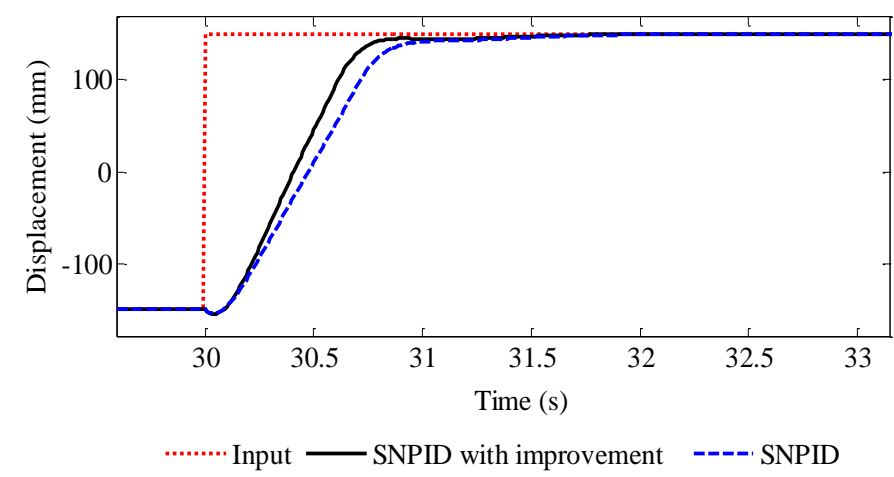

Figure 5. Simulation results for different controllers 
Figure 6 illustrates the changes that occur in the nonlinear gain with respect to either $\alpha$, or both $\alpha$ and $\gamma$. The magnitude of nonlinear gain based on the proposed technique is greater than the existing technique. It is observed that the speed increases according to the increment of $\mathrm{k}(\mathrm{e}, \alpha, \gamma)$. Normally, the robustness of the system is influenced by the increment of speed. However, this does not occur because the value of $\mathrm{k}(\mathrm{e}, \alpha, \gamma)$ keeps changing depending on the error and it returns to the initial value, $\mathrm{k}(\mathrm{e}, \alpha, \gamma)=1$ when the error is zero.

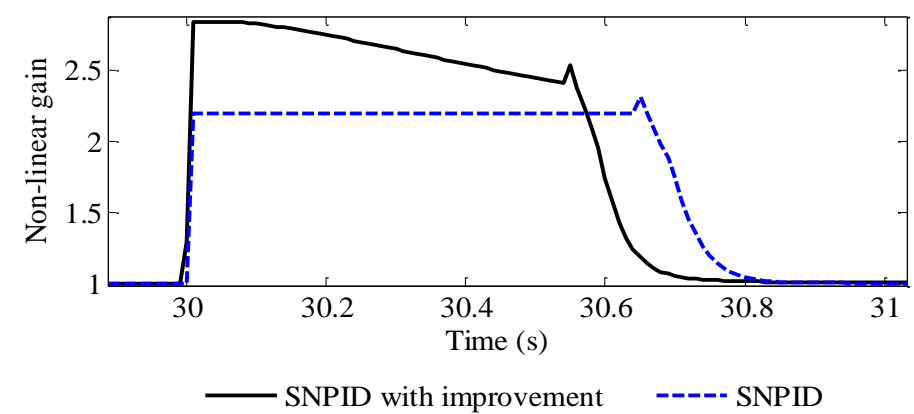

Figure 6. Different actions of nonlinear gain

Figure 7 illustrates the changes of the nonlinear gain in regard to damping frequency, $\omega_{d}$ and peak time, $t_{p}$. The plot shows that the speed of the piston's movement initially increases in reference to the low value of $t_{p}$. In this case, an increment in the damping frequency, $\omega_{d}$ causes it to overshoot. However, the reduction of $k(e, \alpha, \gamma)$ with respect to time prevents this situation from occurring. This condition was performed via the introduction of a new equation of $\gamma$. The significant impact of $\gamma$ is that it vividly helps in the introduction of parameter $\eta$ called deceleration factor as in (3). Previously, in the basic technique of nonlinear function, the value of the denominator of (1) is fixed at 2. As a consequence, the result obtained is not up to par in the perspective of optimizing performance.

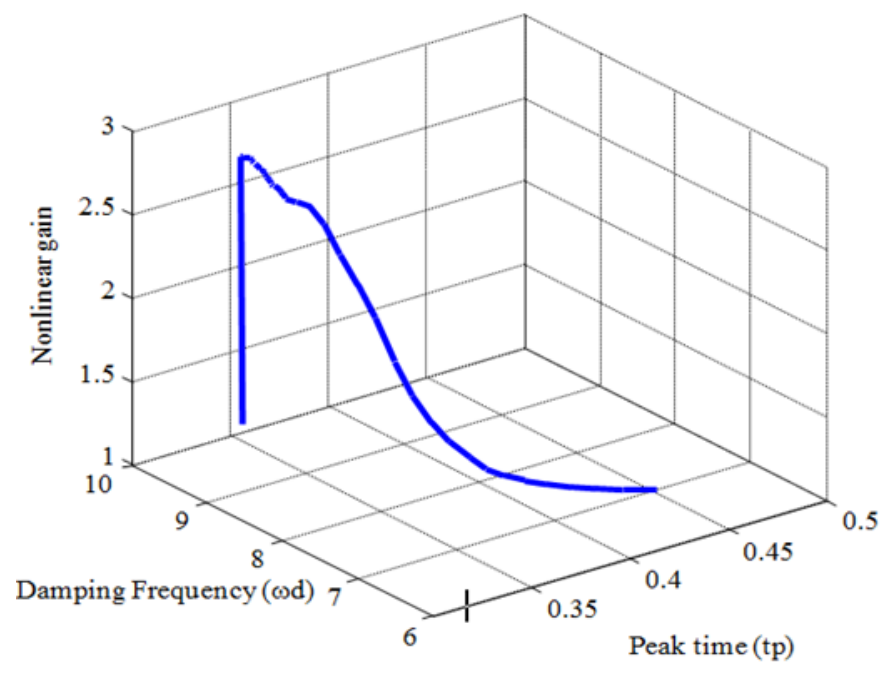

Figure 7. Relationship between nonlinear gain, $k(e)$ and damping frequency $\left(\omega_{d}\right)$

The simulation result is compared with the outcome acquired from the real-time system for verification purposes. It shows that the experimental result is almost equivalent to the simulation result as depicted in Figure 8. The detailed performance based on the multiple step input trajectory is tabulated in Table 3. 


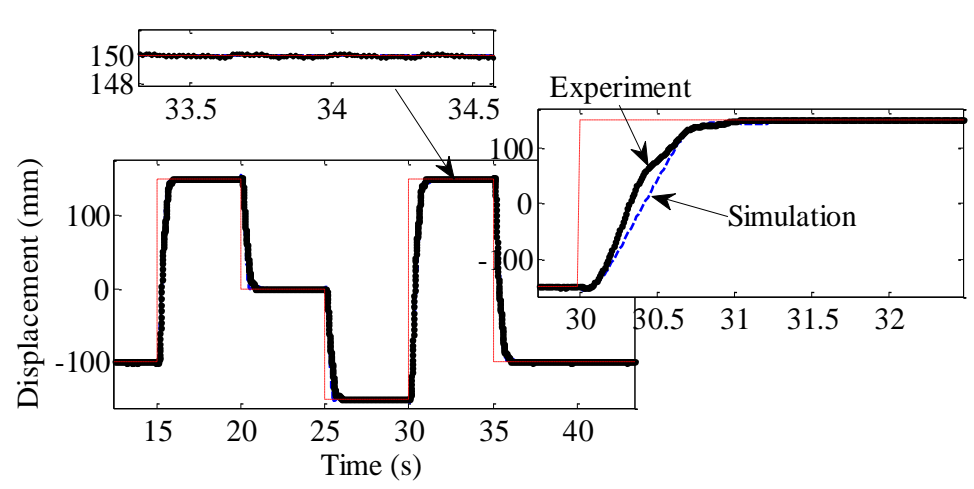

Figure 8. Experiment and simulation outcome

Table 3. Performance of the system via ESN-PID

\begin{tabular}{ccccc}
\hline Direction & Displacement $(\mathrm{mm})$ & $\operatorname{tr}(\mathrm{s})$ & ts $(\mathrm{s})$ & $\mathrm{e}_{\mathrm{ss}}(\mathrm{mm})$ \\
\hline Extend & 250 & 0.405 & 0.711 & 0.005 \\
Retract & 150 & 0.279 & 0.501 & 0.005 \\
Extend & 300 & 0.461 & 0.828 & 0.012 \\
Retract & 250 & 0.401 & 0.712 & 0.006 \\
\hline
\end{tabular}

\section{CONCLUSION}

In this paper, the SNPID controller for pneumatic positioning system shows a significant improvement after the introduction of a new function involving deceleration factor, $\eta$ at the denominator of nonlinear function. The new function was introduced to improve the transient performance of step response. This additional function is easy to be implemented without the need of detailed understanding of the control theory. The performances of the system were examined through simulations and experiments. The changes in the value of the nonlinear gain $\mathrm{k}(\mathrm{e}, \alpha, \gamma)$ were analyzed and attributed to variation of damping frequency and peak time. The results indicated that the proposed improvement were successful to provide better performance compared to the existing one without affecting the steady state performance. For verification purposes, experiments were carried out and found a slight discrepancy between these two results. Experimental tests were conducted at different distances and directions to guarantee the steadiness of the performance.

\section{ACKNOWLEDGEMENTS}

This research is supported by Universiti Teknikal Malaysia Melaka (UTeM) and Universiti Teknologi Malaysia (UTM) through Short Term - High Impact grant scheme (PJP-HI) with reference number of PJP/2017 FTK/HI/S01535 and Research University Grant (GUP) Tier 1 vote no. Q.J130000.7123.00H36. Authors are grateful to UTeM and UTM for supporting the present work. A special thanks also goes to the Ministry of Higher Education.

\section{REFERENCES}

[1] S. R. Pandian, F. Takemura, Y. Hayakawa, and S. Kawamura, "Pressure observer-controller design for pneumatic cylinder actuators," IEEE/ASME Transactions on Mechatronics, 2002; 7: 490-499, 2002.

[2] Siti Fatimah Sulaiman, M.F. Rahmat, A.A.M.Faudz, Khairuddin Osman, S.N.S.Salim, S.I. Samsudin, A.R.Azira, "Enhanced Position Control for Pneumatic System by Applying Constraints in MPC Algorithm," International Journal of Electrical and Computer Engineering (IJECE), 7(3): 1633-1642, 2017.

[3] X. Brun, D. Thomasset, and E. Bideaux, "Influence of the process design on the control strategy: application in electropneumatic field. Control Engineering Practice, 10(7): 727-735, 2002.

[4] F. Xiang and J. Wikander, "QFT control design for an approximately linearized pneumatic positioning system," Int. J. Robust Nonlinear Control, 13(7): 675-688, 2003.

[5] H. Schulte and H. Hahn, "Fuzzy state feedback gain scheduling control of servo-pneumatic actuators," Control Engineering Practice, 12(8): 639-650, 2004.

[6] M. A. Raul Guenther, E. C. Perondi, E. R. DePieri, and A. C. Valdiero, "Cascade Controlled Pneumatic Positioning System with LuGre Model Based Friction Compensation," Journal of the Brazilian Society of Mechanical Sciences and Engineering. 28(1): 48-57, 2006. 
[7] A. A. M. Faudzi, K. Osman, M. F. Rahmat, N. m. D. Mustafa, M. A. Azman, and K. Suzumori, "Nonlinear Mathematical Model of an Intelligent Pneumatic Actuator (IPA) Systems: Position and Force Controls," IEEE/ASME International Conference on Advanced Intelligent Mechatronics, Taiwan, 1105-1110, 2012.

[8] S.N.S.Salim, M.F. Rahmat, A. A. M. Faudzi, Z. H. Ismail, N.H. Sunar, SA Samsudin, "Robust Control Strategy for Pneumatic Drive System via Enhanced Nonlinear PID Controller," International Journal of Electrical and Computer Engineering (IJECE), 4(5): 658-667, 2014.

[9] E. Wolbrecht and L. Wells, “Adaptive Pneumatic Control With Spool Deadband Compensation,” International Journal of Fluid Power, 13(1): 25-37, 2012.

[10] Ramhuzaini Abd. Rahman \& Nariman Sepehri, "Pneusimulator: A simulation software for studying performance of controllers in pneumatic actuating systems," International Journal of Fluid Power, 18(1): 70-72, 2017.

[11] M. E. U. J. Araújo, J. R. T. Gadelha, W. M. Santos, A. L. Maitelli, and F. M. U. Araújo, "Nonlinear Predictive Control System for Stiction Compensation in Electropneumatic Control Valves." Journal of Control Science and Engineering, 2018(1): 1-15, 2018.

[12] Pardeep Rohillaa, Vineet Kumar and Feras Al-Hakkak. "Fuzzy gain scheduling of PID controller for stiction compensation in pneumatic control valve," Journal of Computational and Applied Research in Mechanical Engineering (JCARME), 8(2): 165-174, 2019.

[13] K. Ahn and T. Thanh, "Nonlinear PID control to improve the control performance of the pneumatic artificial muscle manipulator using neural network," Journal of Mechanical Science and Technology, 19(1): 106-115, 2005.

[14] X. Gao and Z.-J. Feng. Design study of an adaptive Fuzzy-PD controller for pneumatic servo system. Control Engineering Practice. 2005;13: 55-65, 2005.

[15] C. Junyi, C. Binggang, Z. Xining, and W. Guangnui, "Fractional Proportional Integral Control for Pneumatic Position Servo Systems," IEEE/ASME International Conference on Mechtronic and Embedded Systems and Applications (MESA), Beijing, 2008: 347-352.

[16] S. Cho, "Trajectory tracking control of a pneumatic X-Y table using neural network based PID control," International Journal of Precision Engineering and Manufacturing, 10(5): 37-44, 2009.

[17] M. Taghizadeh, F. Najafi, and A. Ghaffari, "Multimodel PD-control of a pneumatic actuator under variable loads," Int J Adv Manuf Technol, 48(5-8): 655-662, 2010.

[18] M. F. Rahmat, S. N. S. Salim, A. A. M. Faudzi, Z. H. Ismail, S. I. Samsudin, N. H. Sunar, et al.. "Non-linear Modeling and Cascade Control of an Industrial Pneumatic Actuator System," Australian Journal of Basic and Applied Sciences. 5(8): 465-477, 2011.

[19] M. F. Rahmat, S. N. S. Salim, N. H. Sunar, A. A. M. Faudzi, Z. H. Ismail, and K. Huda, "Identification and nonlinear control strategy for industrial pneumatic actuator," International Journal of the Physical Sciences. 7(17): 2565-2579, 2012.

[20] S. N. S. Salim, M. F. Rahmat, A. A. Faudzi, and Z. Ismail, "Position control of pneumatic actuator using an enhancement of NPID controller based on the characteristic of rate variation nonlinear gain," International Journal of Advanced Manufacturing Technology, 75(1-4): 181-195, 2014.

[21] K. Sato and Y. Sano. "Practical and intuitive controller design method for precision positioning of a pneumatic cylinder actuator stage," Precision Engineering, 38(10): 703-710, 2014.

[22] S.-C. Hsu and C.-Y. Lin, "Periodic motion control of a heavy duty pneumatic actuating table using low-cost position sensors and hybrid repetitive control," IEEE International Symposium on Industrial Electronics (ISIE), $1-6,2013$.

[23] K. Ahn and T. Thanh, "Nonlinear PID control to improve the control performance of the pneumatic artificial muscle manipulator using neural network," Journal of Mechanical Science and Technology, 19(1): 106-115, 2005.

[24] X. Gao and Z.-J. Feng, "Design study of an adaptive Fuzzy-PD controller for pneumatic servo system," Control Engineering Practice, 13(1): 55-65, 2005.

[25] S. N. S. Salim, M. F. Rahmat, A. Mohd Faudzi, Athif, Z. H. Ismail, and N. Sunar, "Position Control of Pneumatic Actuator Using Self-Regulation Nonlinear PID,” Mathematical Problems in Engineering, vol. 2014: 12, . 2014.

\section{BIOGRAPHIES OF AUTHORS}

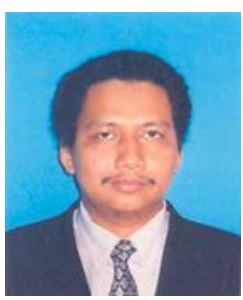

Syed Najib Syed Salim received M.Eng. (Electrical) from Universiti Teknologi Malaysia in 2003. He completed his Ph.D degree in Electrical Engineering (specialized in Control System Engineering) at Universiti Teknologi Malaysia in 2015. Currently, he is a senior lecturer at the Faculty of Engineering Technology Universiti Teknikal Malaysia Melaka, Malaysia. His field of specialization includes control systems design, Mechatronics, Instrumentation and Industrial Automation. 


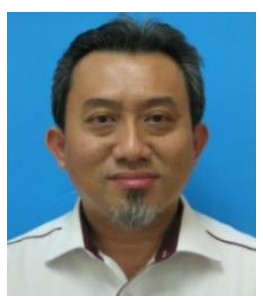

Mohd Fua'ad Rahmat received degree in Electrical Engineering at Universiti Teknologi Malaysia in 1989. He started his Master degree by taught course specialized in Control System Engineering and graduated in 1993 at The University of Sheffield, UK. Subsequently, he pursued his $\mathrm{PhD}$ degree in Electronic Instrumentation Engineering at the School of Engineering, Sheffield Hallam University, UK and graduated in 1996. Currently, he is a Professor in the Department of Control and Mechatronics Engineering, Faculty of Electrical Engineering, Universiti Teknologi Malaysia Skudai Johor. His field of specialization include System Identification and Estimation, Signal Processing, Process Tomography for Industrial Process, Process Control Instrumentation, Sensors and Actuators, Hydraulic and Pneumatic System.

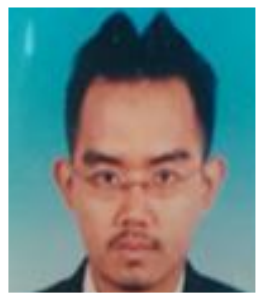

Lokman Abdullah received the B.Eng. degree in manufacturing engineering from International Islamic University of Malaysia (IIUM), in 2005, the M.Sc. degree in manufacturing systems engineering from Coventry University, UK, in 2008, and the Ph.D. degree in engineering from Universiti Teknikal Malaysia Melaka (UTeM), Malaysia, in 2014. He is currently a Lecturer with the Department of Robotics and Automation, Faculty of Manufacturing Automation, Universiti Teknikal Malaysia Melaka, Malaysia. His fields of interest are in control systems, motion control, mechatronics, and industrial automation

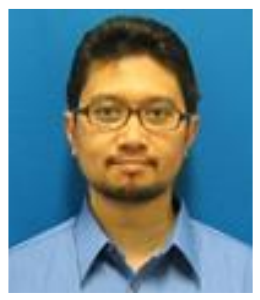

Shamsul Anuar Shamsudin received his Ph.D. in Engineering from the University of Dayton in Dayton, Ohio, USA in May 2013. His research interests include mechanisms, machine component design, engineering design methods, engineering graphics and automation. He has been with UTeM (and KUTKM) for 14 years. He is a senior lecturer at the Faculty of Mechanical Engineering in UTeM.

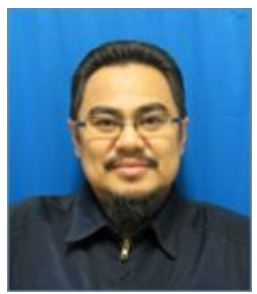

Maslan Zainon received his M.Sc. in Electrical Engineering with Power Electronics from the University of Bradford, UK, in 2005. He also holds a B.Eng. (Hons) in Electrical and Electronic Engineering (Manchester Metropolitan University, UK) in 1998, and a Diploma in ElectroMechanical Engineering (Politeknik Kota Bharu, Kelantan, Malaysia) in 1994. His research interests include industrial automation, control and monitoring systems design, renewable energy (solar photovoltaic) as well as technical and vocational education and training (TVET). He has been with Universiti Teknikal Malaysia Melaka (UTeM), formerly known as Kolej Universiti Teknikal Kebangsaan Malaysia (KUTKM), since 2003. He is a senior lecturer at the Faculty of Engineering Technology, UTeM.

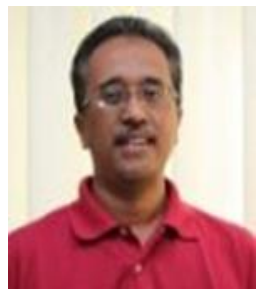

Ahmad Fairuz Muhammad Amin received the B.Eng. degree (with honours) in Electrical and Electronic Engineering (Computer and Communication Eng) from the Universiti Sains Malaysia, Pulau Pinang, Malaysia, in 1988, and the M.Sc. degree in Computer Science from the Universiti Putra Malaysia, Selangor, Malaysia, in 2004. Since then, he joined Universiti Multimedia, Malaysia, in 1996 as System Engineer. He is currently a Lecturer at Universiti Teknikal Malaysia Melaka and main areas of research interest are computer networking and embedded system design. 